\title{
Update on Clinical Manifestation in Acute Low-Tone Hearing Loss
}

\author{
Hyunjung Kim, Hoyoung Lee, Young-Chan Kim, Euyhyun Park, \\ June Choi, Yoon Chan Rah, Hak Hyun Jung, and Gi Jung Im iD \\ Department of Otolaryngology-Head and Neck Surgery, Korea University College of Medicine, Seoul, Korea
}

\author{
급성 저음역 난청의 임상양상 업데이트 \\ 김현정 - 이호영 - 김영찬 · 박의현 · 최 준 · 나윤찬 - 정학현 · 임기정 \\ 고려대학교 의과대학 이비인후-두경부외과학교실
}

\author{
Received October 22, 2019 \\ Revised April 8, 2020 \\ Accepted April 13, 2020 \\ Address for correspondence \\ Gi Jung Im, MD \\ Department of Otolaryngology- \\ Head and Neck Surgery, \\ Korea University \\ College of Medicine, \\ 73 Goryeodae-ro, Seongbuk-gu, \\ Seoul 02841, Korea \\ Tel +82-2-920-5486 \\ Fax $+82-2-925-5233$ \\ E-mail logopas@korea.ac.kr
}

Background and Objectives Acute low-tone hearing loss (ALHL) is gaining attention as an independent disease identity with close association with endolymphatic hydrops and early stage Meniere's disease (MD). This study aims to compare patients of ALHL with patients exhibiting low-tone hearing loss and ear fullness without vertigo in various audio-vestibular assessments and in progression to overt MD.

Subjects and Method A total of 249 patients with low-tone hearing loss with ear fullness without vertigo was enrolled in this study. Of these patients, 58 patients met criteria for ALHL, which was defined as having an average hearing loss of $\geq 30 \mathrm{~dB}$ at 125,250 , and $500 \mathrm{~Hz}$ and $\leq 20$ $\mathrm{dB}$ at 2, 4, and $8 \mathrm{kHz}$. Demographics, electrocochleography (ECoG) abnormality, rate of hearing improvement, vestibular functions, and progression to MD were analyzed.

Results An average low-tone hearing loss of ALHL patients was $42.8 \mathrm{~dB}$, which recovered to $18.9 \mathrm{~dB}$ following a combined treatment of diuretics and oral steroid therapy. The hearing recovery rate of this group was $87.9 \%$ and the ECoG abnormality ratio was $42.5 \%$. Also, $15.5 \%$ of ALHL patients eventually progressed to MD.

Conclusion This study described demographics and characteristics of ALHL, demonstrating a successful response to the combined treatment of diuretics and oral steroid. Also, this report demonstrated a close relationship between the degree of low-tone hearing loss and ECoG abnormality and observed the progression to MD in ALHL patients. These data can be usefully applied in clinical setting to explain clinical outcomes of ALHL.

Korean J Otorhinolaryngol-Head Neck Surg 2020;63(9):403-8

Key Words Diuretics $\cdot$ Electrocochleography $\cdot$ Hearing loss $\cdot$ Meniere disease $\cdot$ Steroids.

\section{Introduction}

Acute low-tone hearing loss (ALHL), which was previously classified as a subset of sudden sensorineural hearing loss (SNHL), is now presumed to be an independent disease identity as an early stage of Meniere's disease (MD) since its first

This is an Open Access article distributed under the terms of the Creative Commons Attribution Non-Commercial License (https://creativecommons.org/licenses/by-nc/4.0) which permits unrestricted non-commercial use, distribution, and reproduction in any medium, provided the original work is properly cited. description by Abe in 1982. ${ }^{1)}$ Patients with ALHL frequently complain symptoms such as tinnitus, ear fullness, hearing changes and autophony, some of which are distinctive symptoms noted in patients with MD and endolymphatic hydrops. Clinical features of ALHL include predominance of female patients, peak incidence during fourth decade of life, tinnitus, ear fullness, autophony, mild dizziness, and suspicion of bilateral involvement. ${ }^{2)}$ ALHL is known to show complete or partial spontaneous recovery in more than $80 \%$ of patients with- 
in 3 months, but recurrence of low-tone loss or progression to MD may occur in $10-20 \%$ of patients. ${ }^{3)}$ Although audiometric definition of ALHL is not fully established, Study Group for Acute Profound Deafness Research Committee of the Ministry of Health, Labor, and Welfare of Japan defines ALHL as sum of hearing levels in affected ears at three low frequencies $(125,250$, and $500 \mathrm{~Hz})$ as $70 \mathrm{~dB}$ or more, and the sum of hearing levels at three high frequencies $(2,4$, and $8 \mathrm{kHz})$ as $60 \mathrm{~dB}$ or less. ${ }^{4)}$ In the article by Choi, et al., ${ }^{5)}$ audiometric diagnostic criteria defines ALHL as average hearing threshold at the three low frequencies as $30 \mathrm{~dB}$ or more, and average hearing threshold at three higher frequencies as $20 \mathrm{~dB}$ or less. In the previous study, demographic data of patients with low-tone hearing loss of more than $10 \mathrm{~dB}$ and ear fullness without vertigo was analyzed. $\left.{ }^{6}\right)$ This data was compared to the ALHL subgroup classified according to the recent diagnostic criteria as described above. Response to oral steroid and diuretic treatment in each patient group was evaluated and electrocochleography $(\mathrm{ECoG})$ results were compared amongst the subclassifications of low-tone hearing loss groups. Also, vestibular function test results were compared between the affected and the normal ear in ALHL group. Some of the limitations from the previous study were small number of patient enrollment and lack of evaluation of progression to MD. ${ }^{6}$ This study aims to compensate some of these limitations by analyzing findings above with greater number of patients over longer follow up periods and also by analyzing progression to MD.

\section{Subjects and Method}

\section{Study design}

This retrospective study was approved by Institutional Review Board of the Medical Center (IRB No. 2018AN0429). All patients who visited our clinic with low-tone hearing loss of more than $10 \mathrm{~dB}$ at 125, 250, and $500 \mathrm{~Hz}$ and ear fullness without vertigo from 2010 to 2018 were enrolled in the study (symptom onset within 2 weeks). Patients who visited the clinic with above symptoms were noted separately on their first visit for further chart review in the future.

The criteria for ALHL without vertigo were as follows: 1) acute onset SNHL with ear fullness within 2 weeks with normal tympanic membrane ear and middle ear anatomy; 2) an average hearing threshold of $\geq 30 \mathrm{~dB}$ at 125,250 , and $500 \mathrm{~Hz}$ and $\leq 20 \mathrm{~dB}$ at 2, 4 , and $8 \mathrm{kHz}$; 3) hearing loss not of typical sudden SNHL defined as a hearing impairment of at least 30
$\mathrm{dB}$ over at least three contiguous frequencies, occurring over a period of 72 hours or less; 4) no vertigo, spontaneous nystagmus, or known cause of SNHL; and 5) normal brain pathology confirmed by posterior-fossa MRI. ${ }^{6}$ Patients with "no significant brain tumor/lesion" by brain/posterior-fossa MRI were excluded from the study.

These patients underwent audio-vestibular assessments, posterior-fossa MRI, and medical treatment. Medical treatment of low-tone hearing loss consisted of initial $60 \mathrm{mg}$ methylprednisolone which was tapered over course of 14 days and $25 \mathrm{mg} /$ day hydrochlorothiazide at least 3 month duration. Pure tone audiometry (PTA) thresholds were measured at 125, 250, 500, 1000, 2000, 3000, 4000, and $8000 \mathrm{~Hz}$ and tests were performed on the patient's first visit and first, second, fourth, and twelfth week follow-ups. The PTA test results of the first visit were compared with the best result amongst the four follow-up tests. Hearing recovery in ALHL was defined as improvement of mean hearing in three low frequencies $(125,250$, and $500 \mathrm{~Hz})$ by $10 \mathrm{~dB}$ or more from the initial hearing thresholds. ${ }^{4)}$

Audio-vestibular assessments comprised of ECoG, vestibular evoked myogenic potential (VEMP) tests, and caloric tests. External auditory canal recording with $95 \mathrm{dBnHL}$ click stimuli was used for ECoG assessment. Likewise, $90 \mathrm{dBnHL}$ alternating tone burst stimuli was used for cervical VEMP. These tests were performed on the ALHL group and the results of the affected side were compared with those of the normal side. ECoG summating potential (SP)/action potential (AP) ratio of 0.34 or greater was considered abnormal and VEMP interaural amplitude difference (IAD) ratio greater than 0.2 was considered abnormal (KUMC vestibular laboratory standard).

The total low-tone hearing loss group of 249 patients were subdivided into four categories depending on the severity of hearing loss. The first group consists of patients with average low-tone hearing threshold $(125,250$, and $500 \mathrm{~Hz}$ ) between 10 and $20 \mathrm{~dB}$. The second group consists of patients with average low-tone hearing threshold between 20 and $30 \mathrm{~dB}$. The third group is the ALHL group with average low-tone hearing threshold greater than $30 \mathrm{~dB}$ and preserved high-frequency hearing. The fourth group consists of patients with average low-tone threshold greater than $30 \mathrm{~dB}$ combined with increased high-frequency hearing threshold $(2,4$, and $8 \mathrm{kHz})$ greater than $20 \mathrm{~dB}$. The patients were divided into four subclassifications to analyze and compare ECoG abnormality ratio and hearing recovery rate among the four groups. 


\section{Statistical analysis}

Data were presented as mean \pm standard deviation. A paired t-test was used to analyze paired data and analysis of variance was used to analyze multiple groups. Statistical analyses were performed using Statistical Package for Social Sciences (IBM SPSS Statistics 22; IBM Corp., Armonk, NY, USA) and data were considered statistically significant when $p<0.05$.

\section{Results}

\section{Demographic data}

Demographic data are shown in Table 1. Total of 249 patients (mean age: $43.8 \pm 14.1 \mathrm{yrs}$ ) visited our clinic complaining symptoms of low-tone hearing loss and ear fullness without vertigo. Of these patients, 58 patients (mean age: $39.3 \pm$ $12.9 \mathrm{yrs}$ ) satisfied criteria for ALHL. The distributions of sex and affected side are presented in Table 1. The mean ECoG value was $0.31 \pm 0.11$ in the total low-tone hearing loss group and $0.31 \pm 0.10$ in the ALHL group. The VEMP IAD ratio was $0.14 \pm 0.38$ in the total group and $0.18 \pm 0.39$ in the ALHL group. The mean values of ECoG and VEMP IAD results were not significantly different between the total and ALHL group ( $p=0.97$ and $p=0.59$, respectively).

\section{Hearing changes in the low-tone hearing loss group ( $n=249)$}

The total low-tone hearing loss group composed of 249 patients. The initial PTA showed mean low-tone hearing loss of $35.6 \mathrm{~dB}(38.9 \mathrm{~dB}$ at $125 \mathrm{~Hz}, 36.5 \mathrm{~dB}$ at $250 \mathrm{~Hz}$, and $31.3 \mathrm{~dB}$ at $500 \mathrm{~Hz}$ ). The mean low-tone hearing improved to $26.2 \mathrm{~dB}$ (29.1 dB at $125 \mathrm{~Hz}, 26.9 \mathrm{~dB}$ at $250 \mathrm{~Hz}$, and $22.8 \mathrm{~dB}$ at $500 \mathrm{~Hz}$ ) after steroid and diuretics therapy. Fig. 1 shows improvement of hearing loss before and after the combination therapy.

Table 1. Patients demographic data

\begin{tabular}{lcc}
\hline & Low-tone hearing loss & ALHL \\
\hline Number of patients & 249 & 58 \\
Age & $43.8 \pm 14.1$ & $39.3 \pm 12.9$ \\
Gender (men:women) & $75: 174$ & $19: 39$ \\
Affected side (right:left) & $82: 167$ & $21: 37$ \\
ECOG & $0.31 \pm 0.11$ & $0.31 \pm 0.10$ \\
VEMP IAD & $0.14 \pm 0.38$ & $0.18 \pm 0.39$ \\
\hline
\end{tabular}

In total, 249 patients exhibit low-tone hearing loss of more than $10 \mathrm{~dB}$ without vertigo in this study. Out of 249 patients, 58 patients exhibited ALHL. ECOG and VEMP IAD values are not signifcantly different between the two groups. ALHL: acute lowtone hearing loss, ECoG: electrocochleography, VEMP IAD: vestibular evoked myogenic potential inter-aural amplitude difference

\section{Hearing changes in the ALHL group $(n=58)$}

The initial mean low-tone hearing loss was $42.8 \mathrm{~dB}(46.6 \mathrm{~dB}$ at $125 \mathrm{~Hz}, 44.4 \mathrm{~dB}$ at $250 \mathrm{~Hz}$, and $37.4 \mathrm{~dB}$ at $500 \mathrm{~Hz}$ ). The hearing recovered to $18.9 \mathrm{~dB}(20.9 \mathrm{~dB}$ at $125 \mathrm{~Hz}, 20.0 \mathrm{~dB}$ at $250 \mathrm{~Hz}$, and $15.6 \mathrm{~dB}$ at $500 \mathrm{~Hz}$ ) following steroid and diuretics therapy. Hearing recovery by more than $10 \mathrm{~dB}$ was seen in $87.9 \%(51 / 58)$ of patients. Fig. 2 shows improvement of hearing loss before and after the combination therapy. Of 51 patients, $23.5 \%(12 / 51)$ showed hearing recovery between 10 and $20 \mathrm{~dB}, 33.3 \%$ (17/51) between 20 and $30 \mathrm{~dB}, 29.4 \%$ (15/51) between 30 and $40 \mathrm{~dB}$, $11.8 \%(6 / 51)$ between 40 and $50 \mathrm{~dB}$, and 2.0\% (1/51) greater than $50 \mathrm{~dB}$. There was statistically significant positive linear

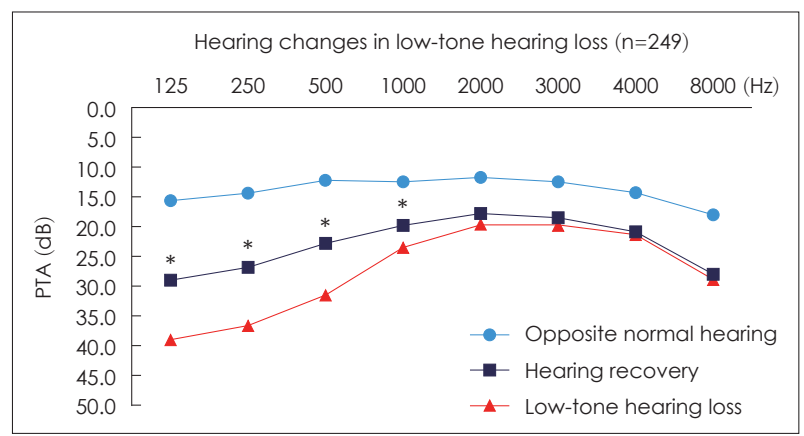

Fig. 1. Low-tone hearing loss and recovery. Low-tone hearing loss group included a total of 249 patients with symptoms of low-tone hearing loss more than $10 \mathrm{~dB}$ and ear fullness without vertigo. Mean low-tone hearing loss was $35.6 \mathrm{~dB}(38.9 \mathrm{~dB}$ at $125 \mathrm{~Hz}, 36.5$ $\mathrm{dB}$ at $250 \mathrm{~Hz}$, and $31.3 \mathrm{~dB}$ at $500 \mathrm{~Hz}$ ) in the PTA. This hearing loss recovers to $26.2 \mathrm{~dB}(29.1 \mathrm{~dB}$ at $125 \mathrm{~Hz}, 26.9 \mathrm{~dB}$ at $250 \mathrm{~Hz}$, and $22.8 \mathrm{~dB}$ at $500 \mathrm{~Hz}$ ) following combined treatment of diuretic and oral steroid therapy. Low-tone hearing loss recovers significantly after therapy, particularly at $125,250,500$, and $1000 \mathrm{~Hz}\left({ }^{*} p<0.001\right.$, paired t-test). Opposite normal hearing is represented in the PTA. PTA: pure tone audiometry.

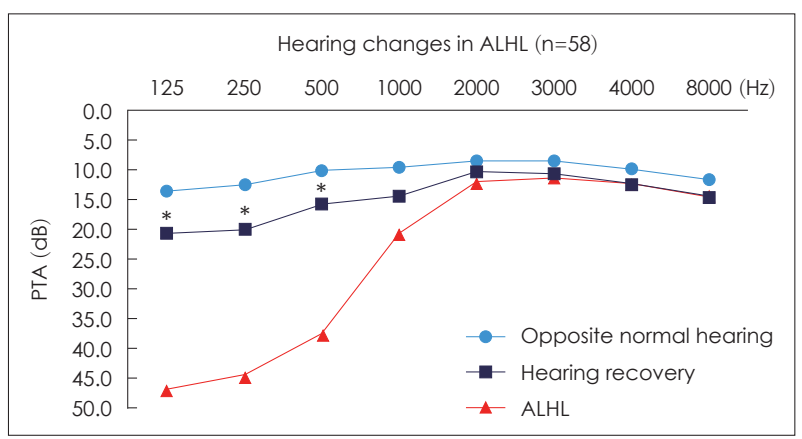

Fig. 2. ALHL and recovery. ALHL group included fifty eight out of 249 patients with low-tone hearing loss more than $10 \mathrm{~dB}$. Mean ALHL was $42.8 \mathrm{~dB}(46.6 \mathrm{~dB}$ at $125 \mathrm{~Hz}, 44.4 \mathrm{~dB}$ at $250 \mathrm{~Hz}$, and $37.4 \mathrm{~dB}$ at $500 \mathrm{~Hz}$ ) in the PTA. This hearing loss recovers to 18.9 $\mathrm{dB}(20.9 \mathrm{~dB}$ at $125 \mathrm{~Hz}, 20.0 \mathrm{~dB}$ at $250 \mathrm{~Hz}$, and $15.6 \mathrm{~dB}$ at $500 \mathrm{~Hz})$ following combined treatment of diuretics and oral steroid therapy. Hearing recovery of more than $10 \mathrm{~dB}$ occurred in $87.9 \%(51 / 58)$ of patients and ALHL recovers significantly after therapy, particularly at 125,250 , and $500 \mathrm{~Hz}\left({ }^{*} p<0.001\right.$, paired t-test). Opposite normal hearing is represented in the PTA. ALHL: acute low-tone hearing loss, PTA: pure tone audiometry. 
relationship between degree of hearing loss and degree of hearing recovery ( ${ }^{*} p<0.001$, univariable linear regression). Fig. 3 shows that majority of patients with severe low-tone hearing loss showed good response to diuretic and steroid treatment, and showed significant recovery.

\section{Sub-classification in low-tone hearing loss}

The total low-tone hearing loss group of 249 patients were subdivided into four categories depending on the severity of hearing loss. Table 2 describes details of sub-classification of the patients. The mean ages of the four subgroups were $36.5 \pm$ $11.4,39.7 \pm 14.2,39.3 \pm 12.9$, and $51.6 \pm 12.8$ years respectively. ALHL composed of 58 out of 249 patients (23.3\%). This group showed the greatest ECoG abnormality ratio (42.5\%), although the correlation between the degree of low-tone hearing loss and ECoG value was not statistically significant ( $p=0.09$, uni-

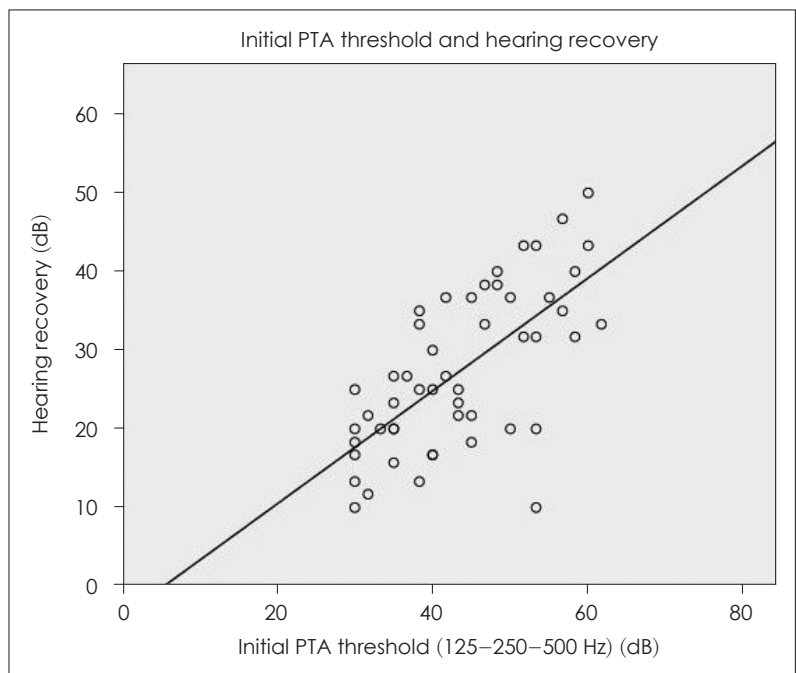

Fig. 3. In acute low-tone hearing loss, there was statistically significant positive linear relationship between degree of hearing loss and degree of hearing recovery $(p<0.001$, univariable linear regression). Majority of patients with severe low-tone hearing loss showed good response to diuretic and steroid treatment, and showed significant recovery. PTA: pure tone audiometry. variable linear regression). ALHL group also showed the greatest hearing recovery rate $(87.9 \%)$, defined as recovery of average hearing in three low frequencies of 125,250 , and $500 \mathrm{~Hz}$ by $10 \mathrm{~dB}$ or more.

\section{Vestibular function test results in ALHL}

The average ECoG SP/AP ratio of the affected ear in the ALHL group was $0.31 \pm 0.11$, which was meaningfully higher than the average value of the normal hearing side $(0.23 \pm 0.07$, $p<0.001)$. The average amplitude of VEMP was $114.4 \pm 125.9$, which was also significantly different from the value of the normal side $(140.1 \pm 106.9, p<0.001)$. Caloric test showed canal paresis of $27.7 \pm 30.5 \%$ and directional preponderance of $4.5 \pm 12.3 \%$. There was no other meaningful correlation between degree of hearing loss and other vestibular function assessments.

\section{Progression to MD in ALHL}

Long-term follow up of the ALHL group was studied to evaluate progression to MD. Amended 2015 criteria recognizes only two categories of MD; definite and probable. Over average period of 7.4 months, 9 out of 58 patients (15.5\%) progressed into definite and 8 out of 58 patients (13.8\%) progressed into probable MD (total 17 out of 58 patients, 29.3\%). Average low-tone hearing loss in definite MD group was 41.8 $\mathrm{dB}$, approximately $38.6 \mathrm{~dB}$ worsened compared to initial PTA. Likewise, the average low-tone hearing loss in probable MD group was $25.3 \mathrm{~dB}$, approximately $11.6 \mathrm{~dB}$ worsened compared to initial PTA. To all patients who progressed into MD, hydrochlorothiazide and occasional alprazolam or dimenhydrinate were prescribed for vertigo symptom control. One patient was treated with isobide solution temporarily. No patient was treated with intratympanic gentamycin or surgical intervention.

Table 2. Sub-classification of low-tone hearing loss

\begin{tabular}{lccr}
\hline & Distribution ratio (\%) & ECoG abnormality ratio (\%) & Hearing recovery rate (\%) \\
\hline $10 \mathrm{~dB} \leq 125,250,500 \mathrm{~Hz}<20 \mathrm{~dB}$ & $50(20.1)$ & $12 / 44(27.3)$ & $36 / 50(72.0)$ \\
$20 \mathrm{~dB} \leq 125,250,500 \mathrm{~Hz}<30 \mathrm{~dB}$ & $48(19.3)$ & $9 / 34(26.5)$ & $41 / 48(85.0)$ \\
$125,250,500 \mathrm{~Hz} \geq 30 \mathrm{~dB} \& 2,4,8 \mathrm{kHz} \leq 20 \mathrm{~dB}(\mathrm{ALHL})$ & $58(23.3)$ & $17 / 40(42.5)$ & $51 / 58(87.9)$ \\
$125,250,500 \mathrm{~Hz} \geq 30 \mathrm{~dB} \& 2,4,8 \mathrm{kHz} \geq 20 \mathrm{~dB}$ & $93(37.3)$ & $26 / 67(38.8)$ & $37 / 93(39.8)$ \\
\hline Total & $249(100)$ & $64 / 185(34.6)$ & $165 / 249(66.3)$
\end{tabular}

All patients of low-tone hearing loss of more than $10 \mathrm{~dB}$ without vertigo were sub-classifed to four groups according to degree of hearing loss, and details of sub-classifcation are described as above. ALHL (23.3\% of all low-tone hearing loss patients) showed highest ECOG abnormality rate of $42.5 \%$ (17/40, ECoG value $\geq 0.34$ ) and greatest hearing recovery rate of $87.9 \%$ (51/58, improvements of average hearing in three low frequencies of 125,250 , and $500 \mathrm{~Hz}$ by more than $10 \mathrm{~dB}$ from initial audiogram). ALHL: acute low-tone hearing loss, ECoG: electrocochleography 


\section{Discussion}

With incidence as high as 65.8 per 100000 population, ALHL is recently receiving more attention regarding its epidemiology, treatment, and prognosis. ${ }^{7)}$ In this study, the demographic data showed marked female preponderance and peak incidence during fourth decade of life, which is comparable to demographic data in previous literature. ${ }^{8)}$ Of 249 patients who visited our clinic complaining of low-tone hearing loss and ear fullness without vertigo, approximately $20 \%$ met criteria for ALHL.

ALHL is now considered an independent disease identity with close relationship to cochlear hydrops and autoimmune response, and numerous investigations have been performed that proved clinical efficacy of steroid and diuretics. ${ }^{9)}$ Diuretics reduce endolymphatic hydrops by osmotic dieresis and glucocorticoids reverse endolymph sodium-potassium imbalance, a treatment combination which gives the best hearing recovery outcome compared to a modality alone. ${ }^{10)}$

Sub-classification of hearing loss depending on severity of hearing loss shows varied hearing recovery rate. The ALHL group showed best hearing recovery rate by $87.9 \%$. When hightone loss was combined with low-tone loss, hearing recovery rate was only $39.8 \%$; this may be due to poorer response to diuretics and steroid in this group of patients with higher average age (51.6 $\pm 12.8 \mathrm{yrs})$ compared to the average age of patients in ALHL group (39.3 \pm 12.9 yrs). Study of such association between degree of hearing loss and recovery allows clinicians to predict prognosis of varying degrees of low-tone hearing loss and explain possible outcomes to patients.

In this study, approximately $27 \%$ (21/78) of patients in the first two groups in the sub-classification of all patients showed ECoG abnormality. Meanwhile, 40\% (43/107) of patients in the last two groups with greater degree of low-tone hearing loss were presented with ECoG abnormality (Table 2). Also, mean ECoG SP/AP ratio of the affected ear of the ALHL group is $0.31 \pm 0.11$, which is significantly higher than the ratio of the normal hearing side $(0.23 \pm 0.07)$ (Table 3$)$. These findings further support cochlear endolymphatic hydrops as main pathophysiology of ALHL. Previous literature explain that enlarged $\mathrm{SP} / \mathrm{AP}$ ratio is associated with greater hearing loss and longer duration of disease. ${ }^{11)}$ Relatively low percentage of SP/AP abnormality in the first two groups of sub-classification may be due to yet undeveloped hair cell malfunction despite presence of endolymphatic hydrops. ${ }^{12)}$

In addition to SP/AP ratio, the mean amplitude of VEMP of
Table 3. Vestibular laboratory results of ALHL

\begin{tabular}{lcc}
\hline & ALHL & Normal hearing side \\
\hline ECOG & $0.31 \pm 0.11$ & $0.23 \pm 0.07$ \\
VEMP & $114.4 \pm 125.9$ & $140.1 \pm 106.9$ \\
Caloric CP (\%) & $27.7 \pm 30.5$ & \\
Caloric DP (\%) & $4.5 \pm 12.3$ & \\
\hline
\end{tabular}

Mean ECOG SP/AP ratio is $0.31 \pm 0.11$, which is significantly higher than normal hearing side $(0.23 \pm 0.07, p<0.001)$. The mean amplitude of VEMP of ALHL group was 114.4 \pm 125.9 , which was also significantly different from normal hearing side (140.1 \pm $106.9, \mathrm{p}<0.001$ ). Caloric test showed CP of $27.7 \pm 30.5 \%$ and DP of $4.5 \pm 12.3 \%$. ALHL: acute low-tone hearing loss, ECoG: electrocochleography, VEMP: vestibular evoked myogenic potential, CP: canal paresis, DP: directional preponderance, SP/AP: summating potential/action potential

ALHL group was $114.4 \pm 125.9$, which was also significantly different from normal hearing side $(140.1 \pm 106.9)$. Saccule is a frequent site of hydrops formation second to cochlea. ${ }^{13)}$ In 2004, Wu and Young ${ }^{13)}$ have reported normal VEMP amplitude in majority of ALHL patients, suggesting that hydrops formation is commonly spared in saccule. However, more recent study by Wang, et al. ${ }^{14)}$ shows simultaneous involvement of saccule and cochlea in ALHL patients, and that IAD of VEMP well correlates with hearing outcomes, and potentially the outcomes of ALHL.

Relationship between ALHL and cochlear hydrops or early stage of MD has been discussed in many previous literatures. 9) In this study, 58 ALHL patients' medical records on symptoms of vertigo and hearing tests in follow up visits were reviewed to evaluate progression to MD. For patients without appropriate records, phone interviews were done. MD was categorized into definite and probable diseases according to consensus document of the Barany Society. Definite MD is defined as two or more episodes of vertigo lasting between 20 minutes and 12 hours with low- to medium- frequency SNHL accompanied by aural symptoms such as tinnitus or fullness and probable MD is defined as two or more episodes lasting between 20 minutes and 24 hours with aural symptoms. ${ }^{15)}$ Over average period of 7.4 months, 9 out of 58 patients $(15.5 \%)$ progressed into definite and 8 out of 58 patients $(13.8 \%)$ progressed into probable MD. This data is comparable to previous reports which described progression rate between 11$24 \%$ (Table 4). ${ }^{16-19)}$

A limitation in this study is that records and hearing tests of only the last follow up were evaluated for studying progression to MD. Therefore, observations of aggravation or improvement of symptoms between the initial and final checkups may be lacking. Also, because vestibular function tests were performed after initiation of medical treatment, some 
Table 4. Rate of progression to definite MD

\begin{tabular}{|c|c|c|}
\hline Study & Rate of progression (\%) & Description of ALHL \\
\hline Yamasoba, et al. ${ }^{16)}$ & 11 & $125,250,500 \mathrm{~Hz}$ SUM $>100 \mathrm{~dB}$ and 2, 4, $8 \mathrm{kHz}$ SUM $<60 \mathrm{~dB}$ \\
\hline Fushiki, et al. ${ }^{17)}$ & 12.5 & $125,250,500 \mathrm{~Hz}$ SUM $>70 \mathrm{~dB}$ and $2,4,8 \mathrm{kHz}$ SUM $<60 \mathrm{~dB}$ \\
\hline Oh, et al. ${ }^{18)}$ & 15.6 & Average of $125,250,500 \mathrm{~Hz} \geq 30 \mathrm{~dB}$ \\
\hline Oishi, et al. ${ }^{19)}$ & $24,17,24$ & $125,250,500 \mathrm{~Hz}$ SUM $\geq 70 \mathrm{~dB}$ (low-, high-, pan-frequency hearing loss, consecutively) \\
\hline Kim HJ & 15.5 & Average of $125,250,500 \mathrm{~Hz} \geq 30 \mathrm{~dB}$ and average of $2,4,8 \mathrm{kHz} \leq 20 \mathrm{~dB}$ \\
\hline
\end{tabular}
In this study, 15.5\% of ALHL patients progressed to MD. Previous studies reported various rates of progression to MD (between $11-$ 24\%). MD: Meniere's disease, ALHL: acute low-tone hearing loss

patients may have recovered partially or perhaps completely from hearing loss at the point of vestibular function tests. This limitation may interfere with accurate interpretation of the test results. Also, there may be recall bias of data for patients who were phone interviewed to recollect their symptoms from a while back.

This study described demographics and characteristics of ALHL, presenting satisfying response to combined treatment of diuretics and oral steroid. Also, close relationship between degree of low-tone hearing loss and ECoG abnormality was reported. Finally, observations of progression to MD in a percentage of ALHL patients were made. These data can be usefully applied in clinical setting to explain clinical outcomes of ALHL.

In this study, average low-tone hearing loss of ALHL group was $42.8 \mathrm{~dB}(46.6 \mathrm{~dB}$ at $125 \mathrm{~Hz}, 44.4 \mathrm{~dB}$ at $250 \mathrm{~Hz}$, and 37.4 $\mathrm{dB}$ at $500 \mathrm{~Hz}$ ) which recovered to $18.9 \mathrm{~dB}$ following combined treatment of diuretics and oral steroid therapy. The hearing recovery rate of this group was $87.9 \%$ and ECoG abnormality ratio was $42.5 \%$, highest amongst all sub-classifications of the total low-tone hearing loss group. In the ALHL group, $15.5 \%$ of patients eventually progressed to MD.

\section{Acknowledgments}

This work was supported by the National Research Grant funded by the Korea Health Industry Development Institute (R1606512, R1621961, R1429733), and research fund (K1609821).

\section{Author Contribution}

Conceptualization: Gi Jung Im. Writing — original draft: Hyunjung Kim. Writing — review \& editing: all authors.

\section{ORCID}

Gi Jung Im

$$
\text { https://orcid.org/0000-0002-9457-4253 }
$$

\section{REFERENCES}

1) Hong SK, Nam SW, Lee HJ, Koo JW, Kim DH, Kim DR, et al. Clinical observation on acute low-frequency hearing loss without vertigo: The role of cochlear hydrops analysis masking procedure as initial prognostic parameter. Ear Hear 2013;34(2):229-35.

2) Imamura S, Nozawa I, Imamura M, Murakami Y. Clinical observations on acute low-tone sensorineural hearing loss. Survey and analysis of 137 patients. Ann Otol Rhinol Laryngol 1997;106(9):746-50.

3) Noguchi Y, Nishida H, Tokano H, Kawashima Y, Kitamura K. Comparison of acute low-tone sensorineural hearing loss versus Meniere's disease by electrocochleography. Ann Otol Rhinol Laryngol 2004;113(3 Pt 1):194-9.

4) Roh KJ, Lee EJ, Park AY, Choi BI, Son EJ. Long-term outcomes of acute low-tone hearing loss. J Audiol Otol 2015;19(2):74-8.

5) Choi HG, Park KH, Seo JH, Kim DK, Yeo SW, Park SN. Clinical and audiologic characteristics of acute low-tone sensorineural hearing loss: Therapeutic response and prognosis. Korean J Audiol 2011;15(1):8-13.

6) Im GJ, Kim SK, Choi J, Song JJ, Chae SW, Jung HH. Analysis of audio-vestibular assessment in acute low-tone hearing loss. Acta Otolaryngol 2016;136(7):649-54.

7) Sato H, Kuwashima S, Nishio SY, Kitoh R, Fukuda S, Hara A, et al. Epidemiological survey of acute low-tone sensorineural hearing loss. Acta Otolaryngol 2017;137(sup565):S34-7.

8) Jung AR, Kim MG, Kim SS, Kim SH, Yeo SG. Clinical characteristics and prognosis of low frequency sensorineural hearing loss without vertigo. Acta Otolaryngol 2016;136(2):159-63.

9) Lee CK, Lee JB, Park KH, Lee HY, Choi MJ, Ban W, et al. Significance of $1 \mathrm{kHz}$ pure-tone threshold in acute low-frequency sensorineural hearing loss. Otol Neurotol 2018;39(10):e950-5.

10) Morita S, Suzuki M, Iizuka K. A comparison of the short-term outcome in patients with acute low-tone sensorineural hearing loss. ORL J Otorhinolaryngol Relat Spec 2010;72(6):295-9.

11) Ge X, Shea JJ Jr. Transtympanic electrocochleography: A 10-year experience. Otol Neurotol 2002;23(5):799-805.

12) Yamamoto $M$, Teranishi $M$, Naganawa $S$, Otake $H$, Sugiura $M$, Iwata $\mathrm{T}$, et al. Relationship between the degree of endolymphatic hydrops and electrocochleography. Audiol Neurootol 2010;15(4): 254-60.

13) Wu CL, Young YH. Vestibular evoked myogenic potentials in acute low-tone sensorineural hearing loss. Laryngoscope 2004; 114(12):2172-5.

14) Wang CT, Fang KM, Young YH, Cheng PW. Vestibular-evoked myogenic potential in the prediction of recovery from acute lowtone sensorineural hearing loss. Ear Hear 2010;31(2):289-95.

15) Lopez-Escamez JA, Carey J, Chung WH, Goebel JA, Magnusson $\mathrm{M}$, Mandalà $\mathrm{M}$, et al. Diagnostic criteria for Menière's disease. J Vestib Res 2015;25(1):1-7.

16) Yamasoba $T$, Sugasawa M, Kikuchi S, Yagi M, Harada T. An electrocochleographic study of acute low-tone sensorineural hearing loss. Eur Arch Otorhinolaryngol 1993;250(7):418-22.

17) Fushiki H, Junicho M, Kanazawa Y, Aso S, Watanabe Y. Prognosis of sudden low-tone loss other than acute low-tone sensorineural hearing loss. Acta Otolaryngol 2010;130(5):559-64.

18) Oh YS, Kim KS, Choi H, Kim KJ. Acute low tone sensorineural hearing loss: Consideration for progression to Meniere's disease. Res Vestibul Sci 2010;9(1):16-20.

19) Oishi N, Inoue Y, Saito H, Kanzaki S, Kanzaki J, Ogawa K. Longterm prognosis of low-frequency hearing loss and predictive factors for the 10-year outcome. Otolaryngol Head Neck Surg 2010;142(4): $565-9$. 